\title{
Monotherapy versus combination therapy of statin and renin-angiotensin system inhibitor in ST-segment elevation myocardial infarction
}

\author{
Yong Hoon Kim ${ }^{1, *}$, Ae-Young Her ${ }^{1, *}$, Myung-Ho Jeong ${ }^{2}$, Byeong-Keuk Kim³ \\ Sung-Jin Hong ${ }^{3}$, Seunghwan Kim ${ }^{4}$, Chul-Min Ahn ${ }^{3}$, Jung-Sun Kim³, \\ Young-Guk $\mathrm{Ko}^{3}$, Donghoon $\mathrm{Choi}^{3}$, Myeong-Ki Hong ${ }^{3}$, Yangsoo Jang ${ }^{3}$ \\ ${ }^{1}$ Division of Cardiology, Department of Internal Medicine, \\ Kangwon National University School of Medicine, Chuncheon, Republic of Korea \\ ${ }^{2}$ Department of Cardiology, Cardiovascular Center, Chonnam National \\ University Hospital, Gwangju, Republic of Korea \\ ${ }^{3}$ Division of Cardiology, Severance Cardiovascular Hospital, \\ Yonsei University College of Medicine, Seoul, Republic of Korea \\ ${ }^{4}$ Division of Cardiology, Inje University College of Medicine, \\ Haeundae Paik Hospital, Busan, Republic of Korea
}

\begin{abstract}
Background: The beneficial effects of statin and renin-angiotensin system inhibitor (RASI) are well-known. In this retrospective cohort study, 2-year clinical outcomes were compared between monotherapy and combination therapy with statin and RASI in ST-segment elevation myocardial infarction (STEMI) patients after stent implantation.

Methods: A total of 17,414 STEMI patients were enrolled and divided into the three groups (group A: 2448 patients, statin alone; group B: 2431 patients, RASI alone; and group C: 12,535 patients, both statin and RASI). The principal clinical endpoint was the occurrence of major adverse cardiac events (MACEs) defined as all-cause death, recurrent myocardial infarction, and any repeat revascularization. Results: After adjustment, the cumulative incidences of MACEs in group A (adjusted hazard ratio [aHR] 1.337; 95\% confidence interval [CI] 1.064-1.679; $p=0.013)$ and in group B (aHR 1.375; 95\% CI 1.149-1.646; $p=0.001$ ) were significantly higher than in group $C$. The cumulative incidence of all-cause death in group A was significantly higher than that in group C (aHR 1.539; 95\% CI 1.014$-2.336 ; p=0.043)$. The cumulative incidences of any repeat revascularization ( $a H R$ 1.317; $95 \% C I$ $1.031-1.681 ; p=0.028)$, target lesion vascularization, and target vessel vascularization in group $B$ were significantly higher than in group $C$.

Conclusions: A statin and RASI combination therapy significantly reduced the cumulative incidence of MACEs compared with a monotherapy of these drugs. Moreover, the combination therapy showed a reduced all-cause death rate compared with statin monotherapy, and a decreased repeat revascularization rate compared with RASI monotherapy. (Cardiol J 2022; 29, 1: 93-104)
\end{abstract}

Key words: ST-segment elevation myocardial infarction, statin, renin-angiotensin system, long-term outcome

Address for correspondence: Yong Hoon Kim, MD, PhD, Division of Cardiology, Department of Internal Medicine, Kangwon National University School of Medicine, 24289, 156 Baengnyeong Road, Chuncheon City, Gangwon Province, Republic of Korea, tel: +82-33-258-9455, fax: +82-33-258-2455, e-mail: yhkim02@kangwon.ac.kr

Received: 17.09.2019 Accepted: 1.03.2020 Early publication date: 18.03.2020

*The first two authors (Yong Hoon Kim and Ae-Young Her) have contributed equally to this work.

This article is available in open access under Creative Common Attribution-Non-Commercial-No Derivatives 4.0 International (CC BY-NC-ND 4.0) license, allowing to download articles and share them with others as long as they credit the authors and the publisher, but without permission to change them in any way or use them commercially. 


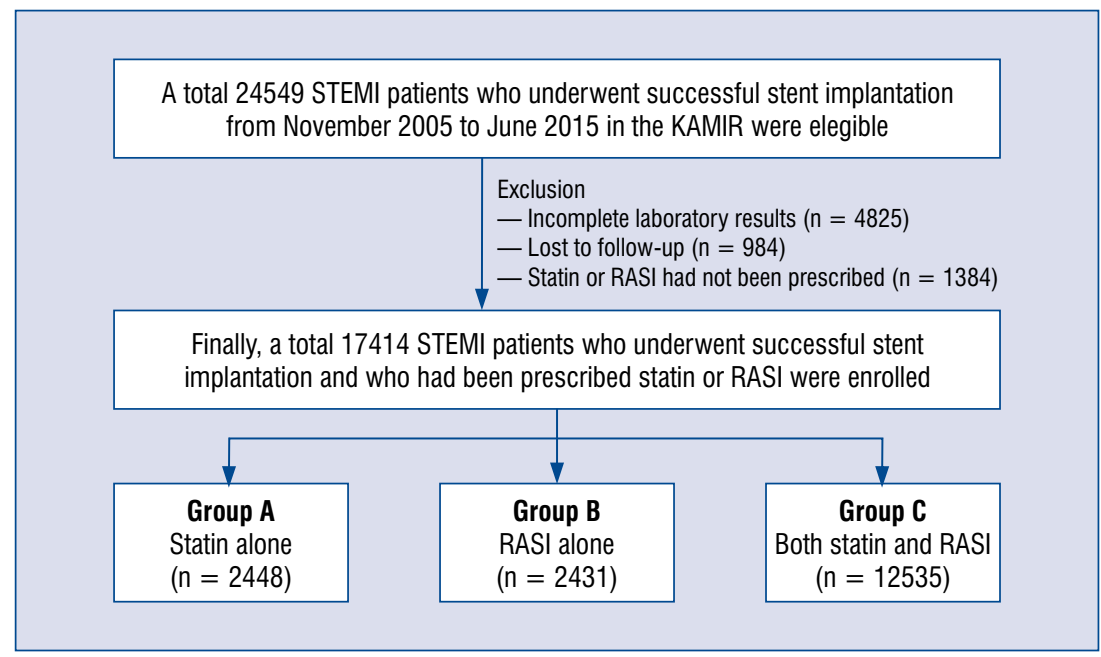

Figure 1. Flow chart; KAMIR — Korea Acute myocardial Infarction Registry; STEMI — ST-segment elevation myocardial infarction; RASI — renin-angiotensin system inhibitor.

\section{Introduction}

Through the inhibition of 3-hydroxy-3-methylglutaryl-coenzyme A (HMG-CoA) reductase activity, statin plays essential roles in primary and secondary prevention of adverse cardiovascular events [1-3]. The European guidelines recommend starting high-intensity statin therapy as early as possible, unless contraindicated, and maintain it long-term in patients with ST-segment elevation myocardial infarction (STEMI) (Class 1A) [4]. Similarly, the American guidelines recommend the use of early high-intensity statin therapy and should be continued in all STEMI patients (Class 1B) [5]. Renin-angiotensin system inhibitors (RASI) are beneficial for reducing mortality in STEMI patients after percutaneous coronary intervention (PCI) [6], and RASI is recommended in the current guidelines as Class 1A [4, 5]. Even though the beneficial effects of statin and RASI are well-known, results focused on the comparative efficacy of combination therapy of statin and RASI, including an angiotensin-converting enzyme inhibitor (ACEI) or angiotensin receptor blocker (ARB) and statin, or RASI monotherapy on the occurrence of major adverse cardiac events (MACEs) during a long-term follow-up period in patients with STEMI who underwent successful stent implantation are limited. In this study, we investigated the difference in clinical outcome parameters between this combination therapy and monotherapy in STEMI patients after successful stent implantation, during a 2-year clinical follow-up period.

\section{Methods}

\section{Study design and population}

The Korea Acute Myocardial Infarction Registry (KAMIR) is a nationwide, prospective, multicenter registry in South Korea, established in November 2005. The KAMIR provides the public and physicians in the "real-world" clinical practice with the demographic characteristic and treatment strategies of the acute myocardial infarction (MI) in Korea [7]. The present study is a non-randomized, multicenter, observational, retrospective cohort study. A total of 24,549 STEMI patients in KAMIR from November 2005 to June 2015 were evaluated. Among them, patients who had the following conditions were excluded: (1) incomplete laboratory results ( $\mathrm{n}=4825,19.7 \%)$, (2) lost to follow-up ( $\mathrm{n}=984,4.0 \%)$, (3) statin or RASI had not been prescribed $(\mathrm{n}=1384,5.6 \%)$. After exclusion, a total of 17,414 STEMI patients who underwent successful stent implantation and who had been prescribed statin or RASI were enrolled. The patients were classified into group A $(2448,14.1 \%)$, group B (2431, 13.9\%), and group C $(12,535,72.0 \%)$, and received statin alone, RASI alone, or both statin and RASI, respectively, as treatment (Fig. 1). The beneficial roles of statin and RASI in STEMI $[4,5]$ are well-known. For these reasons, patients who had not been prescribed these drugs in this study were excluded. The data collection was done via a web-based case report form, at each participating center; well-trained coordinators participated in data collection. The study protocol was approved 
by the ethics committee at each participating center and the Chonnam National University Hospital Institutional Review Board (IRB) ethics committee (CNUH-2011-172) according to the ethical guidelines of the 1975 Declaration of Helsinki. All patients provided written informed consent prior to enrollment. All the 17,414 patients completed a 2 -year clinical follow-up through face-to-face interviews, phone calls, or chart review.

\section{PCI procedure and medical treatment}

Diagnostic coronary angiography and PCI were performed through the femoral and the radial artery approach according to the standard technique [8]. Before PCI, all patients were given loading doses of 200 to $300 \mathrm{mg}$ acetylsalicylic acid (ASA) and 300 to $600 \mathrm{mg}$ clopidogrel, when available; alternatively, $180 \mathrm{mg}$ ticagrelor or $60 \mathrm{mg}$ prasugrel was given. The recommended total duration of dual antiplatelet therapy (DAPT, the combination of ASA [100 mg/day] with clopidogrel [75 mg/day] or ticagrelor [90 mg twice a day] or prasugrel [5-10 mg/ /day]) was more than 12 months to patients who had undergone PCI. Triple antiplatelet therapy $(100 \mathrm{mg}$ cilostazol, twice a day added on to DAPT) was left to the discretion of the individual operators. The statins and their doses were as follows: $10-40 \mathrm{mg}$ of atorvastatin, $5-10 \mathrm{mg}$ of rosuvastatin, $2-4 \mathrm{mg}$ of pitavastatin, $10-40 \mathrm{mg}$ of simvastatin, $10-40 \mathrm{mg}$ of pravastatin, $80 \mathrm{mg}$ fluvastatin, and $50-100 \mathrm{mg}$ lovastatin per day. The RASI used and their doses were as follows: $12.5-75 \mathrm{mg}$ of captopril, $2.5-10 \mathrm{mg}$ of ramipril, 2-8 $\mathrm{mg}$ of perindopril, $1.25-5 \mathrm{mg}$ of cilazapril, 5-10 mg of imidapril, 7.5-15 mg of moexipril, $2.5-10 \mathrm{mg}$ of enalapril, $5-10 \mathrm{mg}$ of lisinopril, $10 \mathrm{mg}$ of fosinopril, 3.75-7.5 mg of zofenopril, 25-100 mg of losartan, 150-300 mg of irbesartan, 40-160 mg of valsartan, $40-80 \mathrm{mg}$ of telmisartan, $10-20 \mathrm{mg}$ of olmesartan, 4-32 mg of candesartan, $600 \mathrm{mg}$ of eprosartan, and 30-120 mg of fimasartan per day.

\section{Study definitions and clinical outcomes}

ST-segment elevation myocardial infarction was defined as the patient who had experienced chest pain with ST-segment elevation $\geq 2 \mathrm{~mm}$ in $\geq 2$ contiguous precordial lead, or $1 \geq 1 \mathrm{~mm}$ in $\geq 2 \mathrm{limb}$ leads, or new-onset left bundle branch block on the admission electrocardiogram [5]. The major clinical endpoint was the occurrence of MACEs, defined as all-cause death, recurrent myocardial infarction (Re-MI), any repeat coronary revascularization, including target lesion revascularization (TLR), target vessel revascularization (TVR), and non-
TVR during the follow-up period. All-cause death was classified as cardiac or non-cardiac. Re-MI was defined as the presence of clinical symptoms, electrocardiographic changes, or abnormal imaging findings of MI, combined with an increase in the creatine kinase myocardial band fraction (CK-MB) above the upper normal limits, or an increase in troponin-T/troponin-I levels above the $99^{\text {th }}$ percentile of the upper normal limit during the follow-up period [5]. TLR was defined as revascularization of the target lesion due to restenosis, or re-occlusion within the stent or $5 \mathrm{~mm}$ in and adjacent of the distal or proximal segment. TVR was defined as revascularization of the target vessel or any segment of the coronary artery containing the target lesion. Non-TVR was defined as revascularization of any segment of the non-target coronary artery.

\section{Statistical analysis}

All statistical analyses were performed using SPSS software, version 20 (IBM; Armonk, NY, USA). For continuous variables, differences among the three groups were evaluated using the analysis of variance or the Jonckheere-Terpstra test, and post-hoc analysis between two groups was carried out using the Hochberg test or Dunnett-T3 test; data are expressed as the means \pm standard deviations. For discrete variables, the differences between two groups among the three groups were analyzed using the $\chi^{2}$ test or the Fisher exact test, as appropriate; data are expressed as counts and percentages. Only meaningful confounding covariates ( $<<0.001$ or those having predictive values) during the multivariable Cox regression analysis, which are listed were included as follows: age, sex (men), left ventricular ejection fraction (LVEF), body mass index (BMI), systolic blood pressure (SBP), diastolic blood pressure (DBP), cardiopulmonary resuscitation (CPR) on admission, primary PCI, hypertension, diabetes mellitus (DM), dyslipidemia, blood N-terminal pro-B-type natriuretic peptide (NT-proBNP), serum creatinine, total cholesterol, triglyceride, low-density lipoprotein cholesterol (LDL-C), ASA, clopidogrel, ticagrelor, prasugrel, beta-blockers (BBs), calcium channel blockers (CCBs), American College of Cardiology/ /American Heart Association (ACC/AHA) lesion type $\mathrm{B} 2$ and $\mathrm{C}$, intravascular ultrasound (IVUS), bare-metal stents (BMS), sirolimus-eluting stent (SES), paclitaxel-eluting stent (PES), everolimus-eluting stents (EES), and biolimus-eluting stents (BES). Various clinical outcomes were estimated using the Kaplan-Meier curve analysis, and dif- 
ferences between groups were compared with the log-rank test. A two-tailed $\mathrm{p}$ value of $<0.05$ indicated statistical significance.

\section{Results}

Baseline clinical, laboratory, angiographic, and procedural characteristics

Table 1 shows the baseline, laboratory, angiographic, and procedural characteristics of this cohort study. The study population is composed of patients who had relatively well preserved LVEF (mean $51.2 \pm 10.9 \%$ ). The number of men among the enrolled patients was the highest in group $\mathrm{C}$. The mean ages of the patients enrolled in group A were older than the other groups. The frequency of primary $\mathrm{PCI}$ was the highest in group $\mathrm{C}$. In group $\mathrm{A}$, the mean blood levels of CK-MB, troponin-I, NTproBNP; the prescription rates of more recently developed antiplatelet agents (e.g., ticagrelor, prasugrel) and $\mathrm{CCB}$ as the discharge medications; the number of CPR on admission; ACC/AHA type C lesion, the use of IVUS and the deployment of zotarolimus-eluting stent (ZES) were the highest. Moreover, the mean diameter of deployed stents was the lowest in group A. In group B, the number of cardiogenic shocks; the mean value of blood glucose, Hemoglobin A1c, creatinine; the number of clopidogrel as the discharge medication, left anterior descending coronary artery (LAD) as an infarctrelated artery, ACC/AHA type B1; and the deployments of BMS, SES, PES, and $\geq 3$-vessel disease were the highest. The mean length of the deployed stents was the shortest in group $\mathrm{B}$. In group $\mathrm{C}$, the mean values of BMI, SBP, DBP, total cholesterol, triglyceride, LDL-C; the prescription rate of ASA and $\mathrm{BB}$ as the discharge medications; the number of hypertensive patients, $\mathrm{LAD}$ as the treated vessel, ACC/AHA type B2 lesion, and EES were the highest. The mean number of deployed stents was not significantly different among the three groups.

\section{Clinical outcomes}

Table 2 shows the cumulative incidences of major clinical outcomes during the 2-year followup period. After adjustment, the cumulative incidences of MACEs in group A (adjusted hazard ratio [aHR]: $1.337 ; 95 \%$ confidence interval [CI]: 1.064-1.679; $\mathrm{p}=0.013$ ) and in group B (aHR: 1.375; 95\% CI: $1.149-1.646 ; \mathrm{p}=0.001$ ) were significantly higher than those in group $\mathrm{C}$ (Table 3 , Fig. 2A). The cumulative incidence of all-cause death in group A was significantly higher than that in group C (aHR: 1.539; 95\% CI: 1.014-2.336; $\mathrm{p}=0.043$; Fig. 2B). The cumulative incidences of any repeat revascularization (aHR: $1.317 ; 95 \% \mathrm{CI}$ : 1.031-1.681; $\mathrm{p}=0.028$; Fig. 2D), TLR (aHR: 1.754; 95\% CI: 0.193-2.580; $\mathrm{p}=0.004$; Fig. $2 \mathrm{E}$ ), and TVR (aHR: $1.539 ; 95 \%$ CI: $1.138-2.082 ; \mathrm{p}=0.005$; Fig. 2F) in group $\mathrm{B}$ were significantly higher than those in group $\mathrm{C}$. However, the cumulative incidences of cardiac, Re-MI, and non-TVR were similar among the three groups before and after adjustment. Table 4 shows the independent predictors for MACEs at 2 years. LVEF < 50\% (aHR: 1.146; 95\% CI: 1.019-1.289; $\mathrm{p}=0.023$ ), DM (aHR: 1.342; 95\% CI: $1.187-1.518 ; \mathrm{p}<0.001)$, multivessel disease (aHR: 1.774; 95\% CI: 1.570-2.005; p < 0.001), cardiogenic shock (aHR: 0.998; 95\% CI: 0.996-1.000; $\mathrm{p}=0.043$ ), and CPR on admission (aHR: 2.240; 95\% CI: 1.784-2.813; $\mathrm{p}<0.001$ ) were significant independent predictors for MACEs.

\section{Discussion}

The main findings of this study are as follows: First, the cumulative incidences of MACEs in group A and group $B$ were significantly higher than those in group C. Second, the cumulative incidence of allcause death in group A was significantly higher than that in group C. Third, the cumulative incidences of any repeat revascularization, TLR, and TVR in group B were significantly higher than those in group C. Finally, the cumulative incidences of cardiac, Re-MI, and non-TVR were similar among the three groups before and after adjustment.

Statins have both fundamental lipid-lowering capacity and additional pleiotropic actions [9]. In patients with STEMI, these pleiotropic activities include cardiovascular death, non-fatal MI, and coronary revascularization rate reduction capabilities $[3,10]$. Even though the relative superiority on the long-term clinical outcome between ACEI and $\mathrm{ARB}$ in acute MI patients is still debatable [11-13], RASI is recommended in patients with STEMI after PCI $[4,5]$. In this study, the cumulative incidence of MACEs, all-cause death, Re-MI, and any repeat revascularization (TLR, TVR, and non-TVR) between group A and group B were similar. It was assumed that the major causative factors for similar results between these two groups are related to a shared process, such as nitric oxide (NO) production [14]. The statins' pleiotropic action include the upregulation and activation of endothelial NO synthase [15], and the accumulated bradykinin after ACEI treatment lead to increased stimulations of the NO production [16]. The combination therapy of statin and RASI compensate unwanted effects 


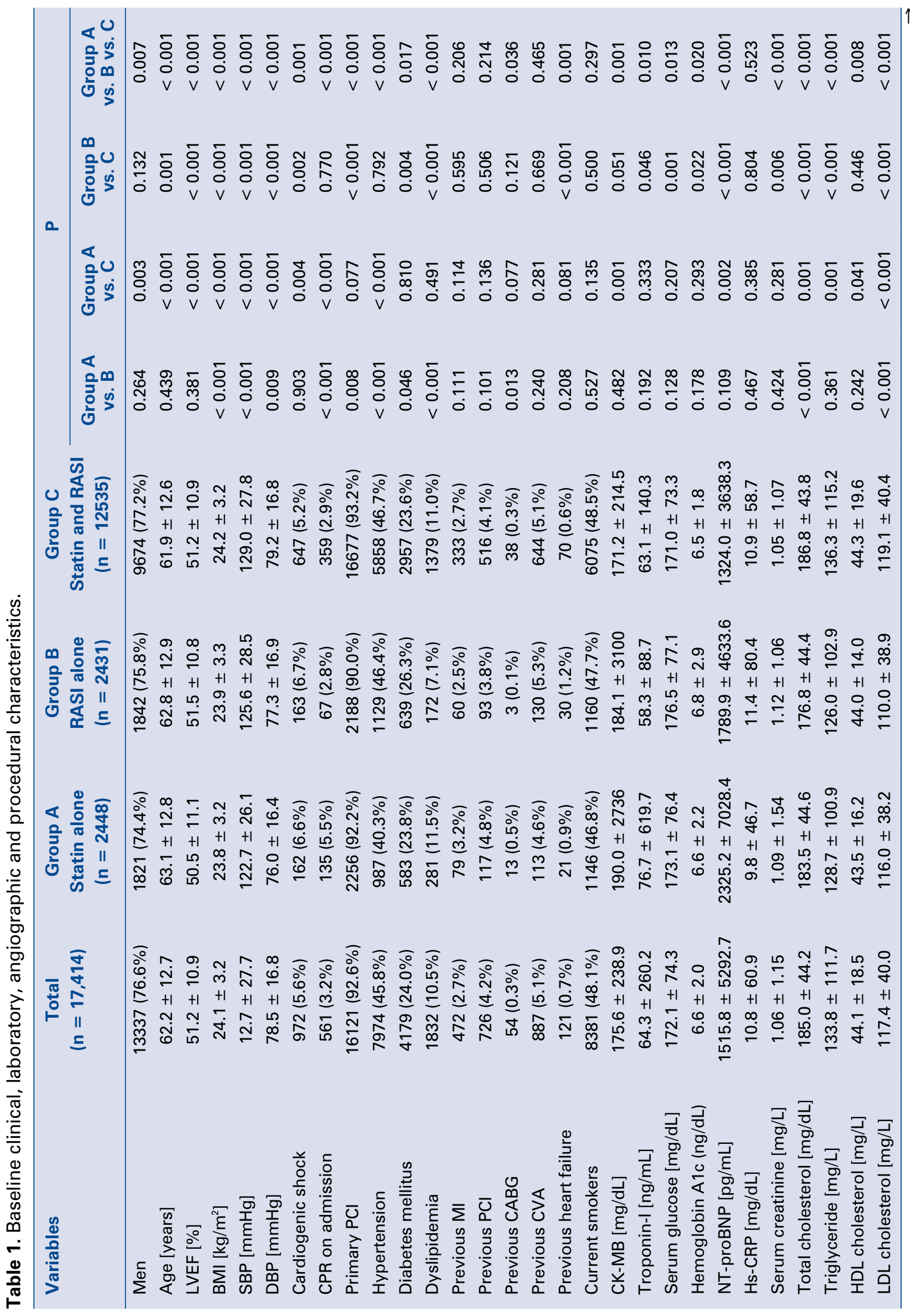




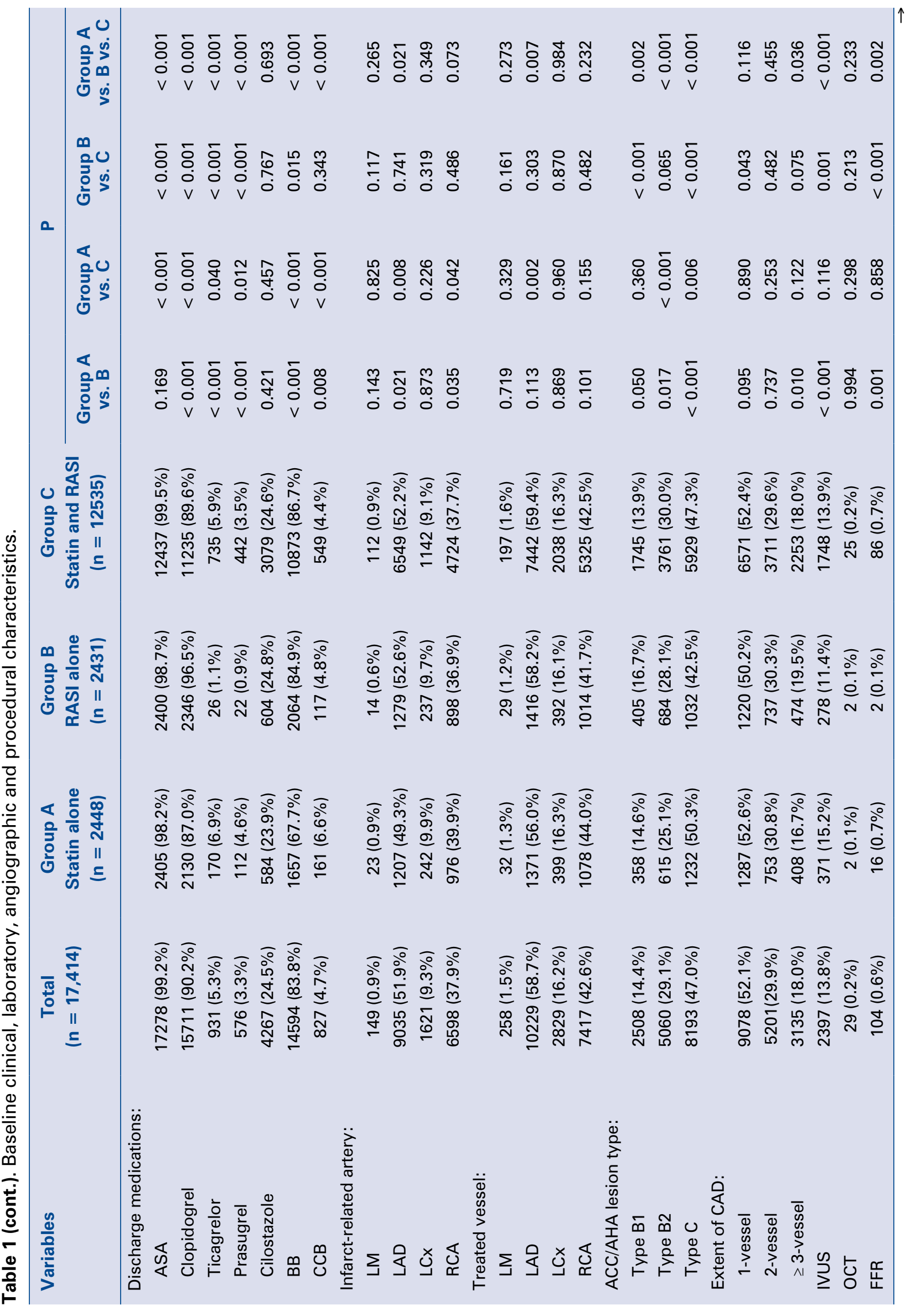




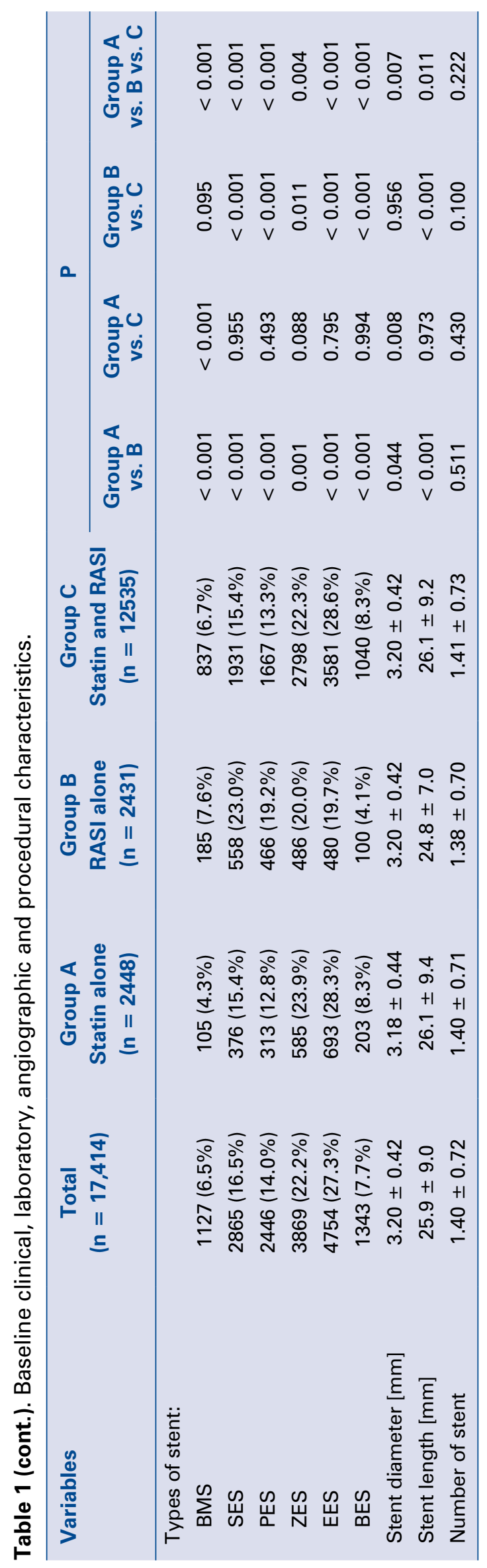

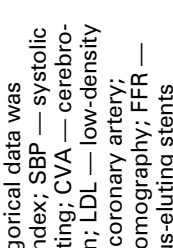

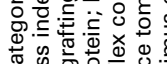

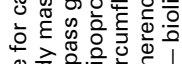

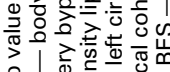

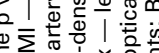

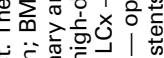

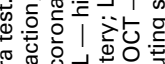

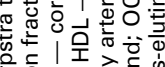

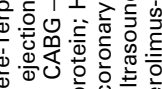

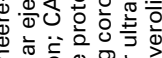

至

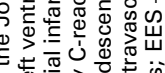

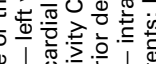

ट्ये

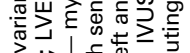

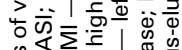

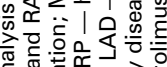

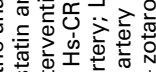

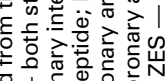

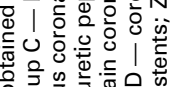

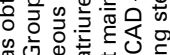

उ.

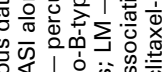

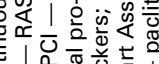

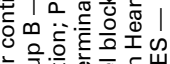

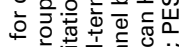

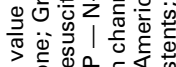

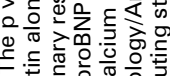

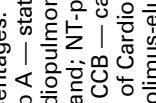

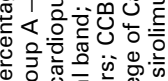

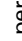

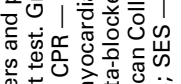

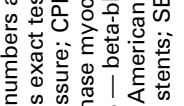

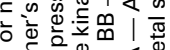

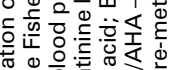

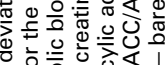

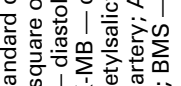

要曹

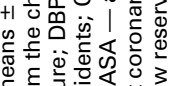

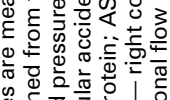

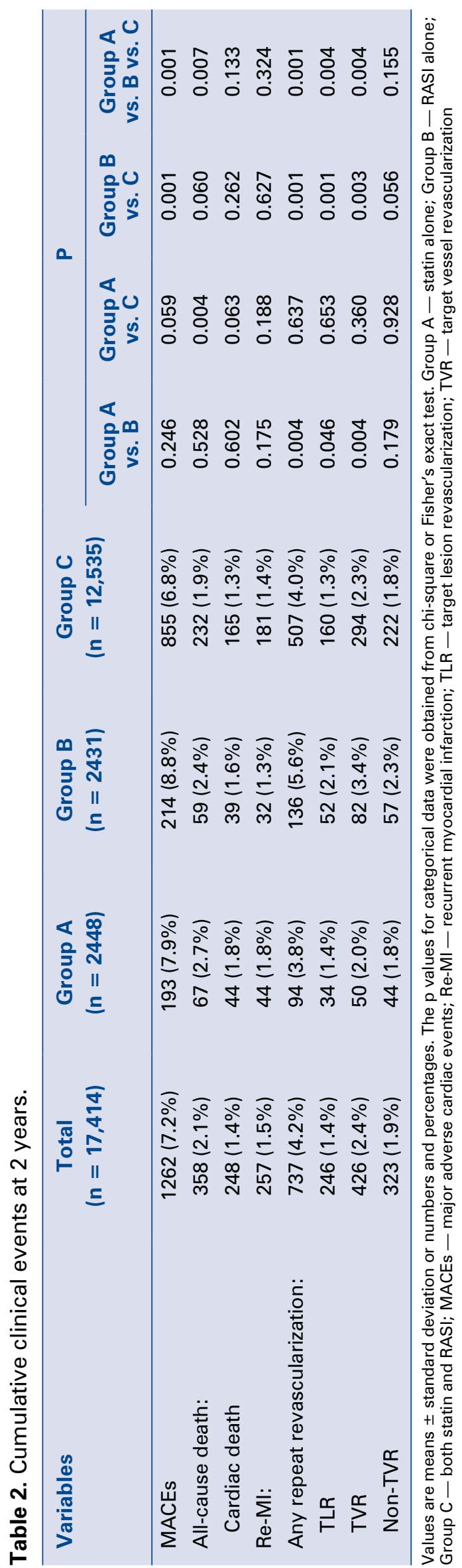


Table 3. Hazard ratio for 2-year major clinical outcomes by Cox-proportional hazard ratio analysis.

\begin{tabular}{|c|c|c|c|}
\hline & \multicolumn{3}{|c|}{ Hazard ratio (95\% confidence interval), P } \\
\hline & Group A vs. B & Group A vs. C & Group B vs. C \\
\hline \multicolumn{4}{|l|}{ MACE: } \\
\hline Unadjusted & $1.057(0.870-1.285), 0.574$ & 1.187 (1.016-1.388), 0.031 & $1.256(1.081-1.459), 0.003$ \\
\hline Adjusted* & $1.093(0.822-1.454), 0.540$ & $1.337(1.064-1.679), 0.013$ & 1.375 (1.149-1.646), 0.001 \\
\hline \multicolumn{4}{|c|}{ All-cause death: } \\
\hline Unadjusted & $1.185(0.835-1.681), 0.343$ & 1.506 (1.148-1.977), 0.003 & $1.275(0.958-1.696), 0.096$ \\
\hline Adjusted* & $1.386(0.803-2.390), 0.241$ & $1.539(1.014-2.336), 0.043$ & $1.172(0.767-1.793), 0.463$ \\
\hline \multicolumn{4}{|l|}{ Cardiac death: } \\
\hline Unadjusted & $1.164(0.756-1.792), 0.490$ & $1.386(0.994-1.933), 0.054$ & $1.192(0.841-1.690), 0.323$ \\
\hline Adjusted* & $1.125(0.528-2.394), 0.768$ & $1.090(0.609-1.951), 0.772$ & $1.244(0.726-2.131), 0.426$ \\
\hline \multicolumn{4}{|l|}{ Re-MI: } \\
\hline Unadjusted & $1.434(0.910-2.262), 0.121$ & $1.276(0.918-1.774), 0.147$ & $1.135(0.779-1.652), 0.510$ \\
\hline Adjusted & $1.048(0.528-2.081), 0.894$ & $1.041(0.637-1.699), 0.873$ & $1.180(0.725-1.921), 0.499$ \\
\hline \multicolumn{4}{|c|}{ Any repeat revascularization: } \\
\hline Unadjusted & 1.377 (1.059-1.791), 0.017 & $1.024(0.822-1.276), 0.831$ & $1.345(1.113-1.625), 0.002$ \\
\hline Adjusted* & $1.038(0.712-1.513), 0.847$ & $1.263(0.926-1.722), 0.141$ & $1.317(1.031-1.681), 0.028$ \\
\hline \multicolumn{4}{|l|}{ TLR: } \\
\hline Unadjusted & $1.450(0.941-2.234), 0.092$ & $1.119(0.773-1.620), 0.119$ & $1.624(0.188-2.221), 0.002$ \\
\hline Adjusted* & $1.111(0.618-1.998), 0.724$ & $1.648(0.999-2.717), 0.050$ & $1.754(0.193-2.580), 0.004$ \\
\hline \multicolumn{4}{|l|}{ TVR: } \\
\hline Unadjusted & 1.555 (1.094-2.210), 0.014 & $1.116(0.827-1.506), 0.474$ & 1.391 (1.089-1.777), 0.008 \\
\hline Adjusted* & $1.184(0.736-1.905), 0.487$ & $1.286(0.857-1.930), 0.224$ & 1.539 (1.138-2.082), 0.005 \\
\hline \multicolumn{4}{|l|}{ Non-TVR: } \\
\hline Unadjusted & $1.230(0.830-1.823), 0.302$ & $1.004(0.755-1.442), 0.796$ & $1.284(0.960-1.718), 0.092$ \\
\hline Adjusted* & $1.067(0.578-1.968), 0.836$ & $1.166(0.721-1.886), 0.531$ & $1.074(0.717-1.610), 0.729$ \\
\hline
\end{tabular}

*Adjusted model was included age, gender (men), LVEF, BMI, SBP, DBP, CPR on admission, primary PCI, hypertension, DM, dyslipidemia, $\mathrm{N}$-proBNP, serum creatinine, total cholesterol, triglyceride, LDL-cholesterol, ASA, clopidogrel, ticagrelor, prasugrel, BB, CCB, ACC/AHA lesion type B2 and C, IVUS, BMS, SES, PES, EES, BES. Abbreviations - see Table 1

of statin and has additive or synergistic effects on endothelial dysfunction, inflammation, and lipid profiles [17-19]. Furthermore, the statin plus RASI combination reduced cardiovascular events more than statin alone and to a greater extent than RASI therapy alone $[18,20]$. As expected, additional beneficial effects of the statin and RASI combination therapy were observed in reducing MACEs compared to that achieved with monotherapy alone in this study. Previous studies have shown that both the statin and the RASI could reduce the death rate and revascularization rate in STEMI patients [21-23]. Additionally, the relative superiority between these two abilities, according to the drugs, was suspected in this study. Figure $2 \mathrm{~B}$ shows the Kaplan-Meier curve of all-cause death among the three groups. The cumulative incidence of all-cause death in group A was continuously higher than that in group $\mathrm{C}$ during the 2 -year follow-up period. However, the cumulative incidence of all-cause death between group $B$ and group $C$ was statistically insignificant. In contrast, the cumulative incidence of total revascularization in group B was continuously higher than that in group $\mathrm{C}$ (Fig. 2D). The cumulative incidence between group $\mathrm{A}$ and group $\mathrm{C}$ was insignificantly different. The Kaplan-Meier curve of TLR (Fig. 2E) and TVR (Fig. 2F) also showed similar patterns among the three groups. Regarding the results of this study, it was cautiously supposed that the possibility that RASI was more likely related with mortality reduction rather than revascularization reduction, and statin was more likely related with repeat revascularization reduction rather than mortality reduction in these STEMI patients after successful stent implantation. In this study, independent predictors for MACEs at 2 years were decreased LVEF (<50\%), DM, multivessel disease, cardiogenic shock, and CPR on admission (Table 4). Therefore, in these situations, the combination therapy of statin and RASI might be helpful in reducing MACEs. 


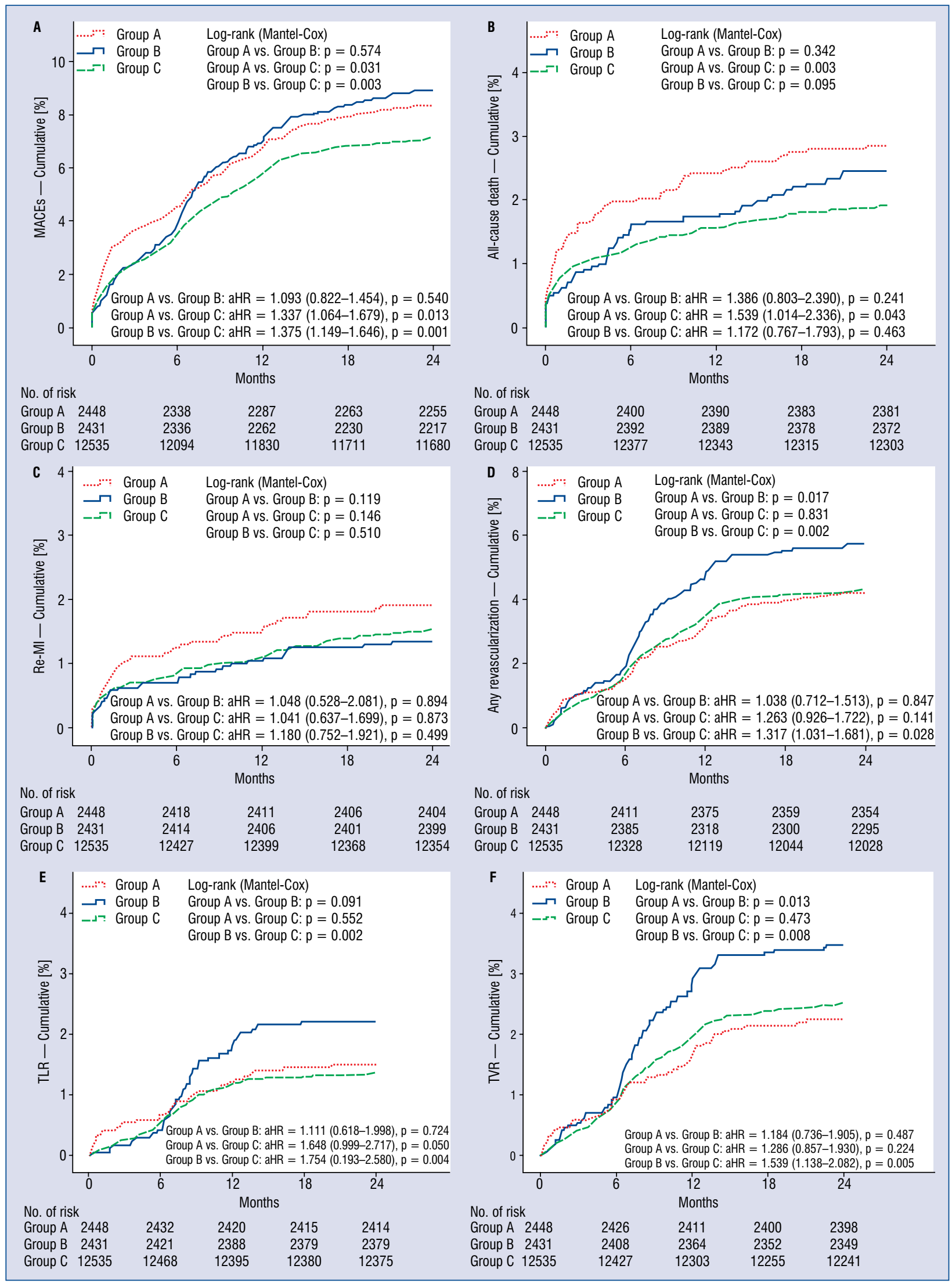

Figure 2. Kaplan-Meier curved analysis for major adverse cardiac events (MACEs; A), all-cause death (B), recurrent myocardial infarction (Re-MI; C), any repeat revascularization (D), target lesion revascularization (TLR; E), and target vessel revascularization (TVR; F) during a 2-year follow-up perioad d; aHR — adjusted hazard ratio. 
Table 4. Multivariate Cox-proportional regression analysis for independent predictor of MACEs.

\begin{tabular}{|c|c|c|c|c|}
\hline \multirow[t]{2}{*}{ Variables } & \multicolumn{2}{|c|}{ Unadjusted } & \multicolumn{2}{|c|}{ Adjusted } \\
\hline & HR (95\% Cl) & $\mathbf{P}$ & HR (95\% CI) & $\mathbf{P}$ \\
\hline \multicolumn{5}{|l|}{ Groups } \\
\hline A vs. B & $1.057(0.870-1.285)$ & 0.574 & $1.063(0.870-1.298)$ & 0.550 \\
\hline A vs. C & 1.187 (1.016-1.388) & 0.031 & $1.208(1.037-1.408)$ & 0.019 \\
\hline B vs. C & 1.256 (1.081-1.459) & 0.003 & $1.217(1.044-1.418)$ & 0.012 \\
\hline Age, $\geq 65$ years & $1.042(1.013-1.071)$ & 0.004 & $1.034(0.990-1.081)$ & 0.129 \\
\hline Gender, men & 1.208 (1.066-1.367) & 0.003 & $1.038(0.899-1.199)$ & 0.281 \\
\hline LVEF, < $<0 \%$ & 1.248 (1.118-1.394) & $<0.001$ & 1.146 (1.019-1.289) & 0.023 \\
\hline Hypertension & $1.211(1.084-1.352)$ & 0.001 & $1.082(0.961-1.217)$ & 0.192 \\
\hline Diabetes mellitus & 1.481 (1.315-1.667) & $<0.001$ & $1.342(1.187-1.518)$ & $<0.001$ \\
\hline Dyslipidemia & $1.066(0.894-1.271)$ & 0.478 & $1.027(0.857-1.232)$ & 0.772 \\
\hline Previous MI & $1.373(1.020-1.849)$ & 0.037 & $1.206(0.890-1.633)$ & 0.227 \\
\hline Multi-vessel disease & $1.897(1.691-2.129)$ & $<0.001$ & $1.774(1.570-2.005)$ & $<0.001$ \\
\hline Current smokers & 1.145 (1.025-1.279) & 0.017 & $1.043(0.869-1.251)$ & 0.842 \\
\hline Cardiogenic shock & 1.301 (1.049-1.614) & 0.017 & $1.135(0.908-1.419)$ & 0.043 \\
\hline CPR on admission & $2.385(1.941-2.972)$ & $<0.001$ & $2.240(1.784-2.813)$ & $<0.001$ \\
\hline ACC/AHA type B2/C & 1.027 (0.902-1.168) & 0.689 & $1.028(0.900-1.174)$ & 0.701 \\
\hline Stent diameter, $<3.0 \mathrm{~mm}$ & $1.242(1.093-1.412)$ & 0.001 & $1.116(0.978-1.273)$ & 0.103 \\
\hline Stent length, $\geq 28 \mathrm{~mm}$ & 1.149 (1.027-1.285) & 0.015 & $1.048(0.934-1.176)$ & 0.421 \\
\hline LAD - IRA & $1.002(0.898-1.119)$ & 0.967 & $1.072(0.881-1.305)$ & 0.541 \\
\hline LAD — treated vessel & 1.158 (1.034-1.298) & 0.011 & $1.190(0.978-1.447)$ & 0.083 \\
\hline IVUS & 1.117 (0.956-1.307) & 0.164 & $1.083(0.923-1.271)$ & 0.329 \\
\hline
\end{tabular}

$\mathrm{HR}$ - hazard ratio; $\mathrm{Cl}$ - confidence interval; IRA — infarct-related artery; other abbreviations — see Table 1

Unlike previous studies [18, 24], the present study population was composed of solely STEMI patients. While some previous studies $[25,26]$ were conducted before the widespread use of statin and dual antiplatelet agents, diverse kinds of statins and newly developed antiplatelet agents were used in this study. More than 50 high-volume University or community hospitals with facilities for primary PCI and onsite cardiac surgery in South Korea participated in this study. Therefore, this comparative study might provide meaningful information to interventional cardiologists regarding the importance of a statin and RASI combination therapy rather than a monotherapy of each drug, and some different clinical outcome characteristics of the statin monotherapy and RASI monotherapy compared with a combination therapy in STEMI patients, after successful stent implantation during a 2-year follow-up period.

\section{Limitations of the study}

This study had several limitations. First, there may be some under-reporting and/or missed data due to limitations of registry data. Second, this study was based on medications at discharge, and this registry data did not include a full detailed data concerning the starting times of statin and RASI therapy, change of prescription doses, long-term adherence, and discontinuation during the follow-up period; these factors might, therefore, act as substantial bias in this study. Third, the achievement of target blood cholesterol level (i.e., LDL-C) was a critical prognostic parameter after statin therapy during the follow-up period. However, the follow-up results could not presented for these lipid profiles due to a limitation of the registry data, which might act as a bias. Fourth, because this study reflectsa multicenter "real-world" clinical practice, diverse kinds and doses of statins and RASI were prescribed; all of which could not be adjusted during statistical analysis, and might be another limitation of this study. Fifth, the selection of either monotherapy or combination therapy of statin and RASI after PCI was left to physician preferences; which might act as selection bias. Sixth, a multivariate analysis was done to strengthen the present results; variables 
not included in this registry may have affected the study outcomes.

\section{Conclusions}

In conclusion, a statin and RASI combination therapy significantly reduced the cumulative incidence of MACEs compared with a monotherapy of these drugs. Moreover, this combination therapy showed a reduced all-cause death rate compared with statin monotherapy, and a decreased repeat revascularization rate compared with RASI monotherapy.

\section{Funding}

This research was supported by a fund (2016ER6304-02) by Research of Korea Centers for Disease Control and Prevention.

\section{Acknowledgments}

The authors thank all of the clinical investigators who contributed time and effort to this study, as well as the Korea Acute Myocardial Infarction (KAMIR) Investigators.

The following investigators took part in the Korea Acute Myocardial infarction Registry (KAMIR): Myung Ho Jeong, MD; Youngkeun Ahn, MD; Sung Chul Chae, MD; Jong Hyun Kim, MD; Seung Ho Hur, MD; Young Jo Kim, MD; In Whan Seong, MD; Donghoon Choi, MD; Jei Keon Chae, MD; Taek Jong Hong, MD; Jae Young Rhew, MD; Doo-Il Kim, MD; In-Ho Chae, MD; Junghan Yoon, MD; Bon-Kwon Koo, MD; Byung-Ok Kim, MD; Myoung Yong Lee, MD; Kee-Sik Kim, MD; Jin-Yong Hwang, MD; Myeong Chan Cho, MD; Seok Kyu Oh, MD; Nae-Hee Lee, MD; Kyoung Tae Jeong, MD; Seung-Jea Tahk, MD; Jang Ho Bae, MD; Seung-Woon Rha, MD; Keum-Soo Park, MD; Chong Jin Kim, MD; Kyoo-Rok Han, MD; Tae Hoon Ahn, MD; Moo-Hyun Kim, MD; Ki Bae Seung, MD; Wook Sung Chung, MD; Ju-Young Yang, MD; Chong Yun Rhim, MD; Hyeon-Cheol Gwon, MD; Seong-Wook Park, MD; Young-Youp Koh, MD; Seung Jae Joo, MD; Soo-Joong Kim, MD; Dong Kyu Jin, MD; Jin Man Cho, MD; Sang-Wook Kim, MD; Jeong Kyung Kim, MD; Tae Ik Kim, MD; Deug Young Nah, MD; Si Hoon Park, MD; Sang Hyun Lee, MD; Seung Uk Lee, MD; Hang-Jae Chung, MD; Jang Hyun Cho, MD; Seung Won Jin, MD; Myeong-Ki Hong, MD; Yangsoo Jang, MD; Jeong Gwan Cho, MD; Hyo-Soo Kim, MD; and Seung Jung Park, MD.

Conflict of interest: None declared

\section{References}

1. Hobbs FD, Banach M, Mikhailidis DP, et al. Is statin-modified reduction in lipids the most important preventive therapy for cardiovascular disease? A pro/con debate. BMC Med. 2016; 14: 4, doi: 10.1186/s12916-016-0550-5, indexed in Pubmed: 26769594.

2. Taylor FC, Huffman M, Ebrahim S. Statin therapy for primary prevention of cardiovascular disease. JAMA. 2013; 310(22): 2451-2452, doi: 10.1001/jama.2013.281348, indexed in Pubmed: 24276813.

3. Baigent C, Keech A, Kearney PM, et al. Cholesterol Treatment Trialists' (CTT) Collaborators. Efficacy and safety of cholesterollowering treatment: prospective meta-analysis of data from 90,056 participants in 14 randomised trials of statins. Lancet. 2005; 366(9493): 1267-1278, doi: 10.1016/S0140-6736(05)67394-1, indexed in Pubmed: 16214597.

4. Ibanez B, James S, Agewall S, et al. ESC Scientific Document Group. 2017 ESC Guidelines for the management of acute myocardial infarction in patients presenting with ST-segment elevation: The Task Force for the management of acute myocardial infarction in patients presenting with ST-segment elevation of the European Society of Cardiology (ESC). Eur Heart J. 2018; 39(2): 119-177, doi: 10.1093/eurheartj/ehx393, indexed in Pubmed: 28886621.

5. O'Gara PT, Kushner FG, Ascheim DD, et al. 2013 ACCF/AHA guideline for the management of ST-elevation myocardial infarction: a report of the American College of Cardiology Foundation/ /American Heart Association Task Force on Practice Guidelines. J Am Coll Cardiol. 2013; 61(4): e78-e7e140, doi: 10.1016/j. jacc.2012.11.019, indexed in Pubmed: 23256914.

6. Kim YH, Her AY, Jeong MHo, et al. Impact of renin-angiotensin system inhibitors on long-term clinical outcomes in patients with acute myocardial infarction treated with successful percutaneous coronary intervention with drug-eluting stents: Comparison between STEMI and NSTEMI. Atherosclerosis. 2019; 280: 166-173, doi: 10.1016/j.atherosclerosis.2018.11.030, indexed in Pubmed: 30529829.

7. Kim Y, Ahn Y, Cho MC, et al. Current status of acute myocardial infarction in Korea. Korean J Intern Med. 2019; 34(1): 1-10, doi: 10.3904/kjim.2018.381, indexed in Pubmed: 30612415.

8. Grech $\mathrm{ED}$. $\mathrm{ABC}$ of interventional cardiology: percutaneous coronary intervention. II: the procedure. BMJ. 2003; 326(7399): 1137-1140, doi: 10.1136/bmj.326.7399.1137, indexed in Pubmed: 12763994.

9. Athyros VG, Kakafika AI, Tziomalos K, et al. Pleiotropic effects of statins--clinical evidence. Curr Pharm Des. 2009; 15(5): 479-489, doi: 10.2174/138161209787315729, indexed in Pubmed: 19199976.

10. Larsen AI, Tomey MI, Mehran R, et al. Comparison of outcomes in patients with ST-segment elevation myocardial infarction discharged on versus not on statin therapy (from the Harmonizing Outcomes With Revascularization and Stents in Acute Myocardial Infarction Trial). Am J Cardiol. 2014; 113(8): 1273-1279, doi: 10.1016/j.amjcard.2014.01.401, indexed in Pubmed: 24576541.

11. McMurray JJV, Pfeffer MA, Swedberg K, et al. Which inhibitor of the renin-angiotensin system should be used in chronic heart failure and acute myocardial infarction? Circulation. 2004; 110(20): 3281-3288, doi: 10.1161/01.CIR.0000147274.83071.68, indexed in Pubmed: 15545527.

12. Messerli FH, Bangalore S. Angiotensin receptor blockers reduce cardiovascular events, including the risk of myocardial infarction. 
Circulation. 2017; 135(22): 2085-2087, doi: 10.1161/CIRCULATIONAHA.116.025950, indexed in Pubmed: 28559492.

13. Cheng J, Zhang W, Zhang X, et al. Effect of angiotensin-converting enzyme inhibitors and angiotensin II receptor blockers on all-cause mortality, cardiovascular deaths, and cardiovascular events in patients with diabetes mellitus: a meta-analysis. JAMA Intern Med. 2014; 174(5): 773-785, doi: 10.1001/jamainternmed.2014.348, indexed in Pubmed: 24687000.

14. Zhang X, Xie YW, Nasjletti A, et al. ACE inhibitors promote nitric oxide accumulation to modulate myocardial oxygen consumption. Circulation. 1997; 95(1): 176-182, doi: 10.1161/01.cir.95.1.176, indexed in Pubmed: 8994434.

15. Laufs U, La Fa, Plutzky J, et al. Upregulation of endothelial nitric oxide synthase by HMG CoA reductase inhibitors. Circulation. 1998; 97(12): 1129-1135, doi: 10.1161/01.cir.97.12.1129, indexed in Pubmed: 9537338.

16. Probstfield JL, O'Brien KD. Progression of cardiovascular damage: the role of renin-angiotensin system blockade. Am J Cardiol. 2010; 105(1 Suppl): 10A-20A, doi: 10.1016/j.amjcard.2009.10.006, indexed in Pubmed: 20102969.

17. Lee HY, Sakuma I, Ihm SH, et al. Statins and renin-angiotensin system inhibitor combination treatment to prevent cardiovascular disease. Circ J. 2014; 78(2): 281-287, doi: 10.1253/circj. cj-13-1494, indexed in Pubmed: 24401609.

18. Athyros VG, Mikhailidis DP, Papageorgiou AA, et al. GREACE Study Collaborative Group. Effect of statins and ACE inhibitors alone and in combination on clinical outcome in patients with coronary heart disease. J Hum Hypertens. 2004; 18(11): 781-788, doi: 10.1038/sj.jhh.1001748, indexed in Pubmed: 15229622.

19. Li $Z$, Iwai $\mathrm{M}, \mathrm{Wu} \mathrm{L}$, et al. Fluvastatin enhances the inhibitory effects of a selective AT1 receptor blocker, valsar$\tan$, on atherosclerosis. Hypertension. 2004; 44(5): 758-763, doi: 10.1161/01.HYP.0000145179.44166.0f, indexed in Pubmed: 15452025 .
20. Athyros VG, Katsiki N, Karagiannis A, et al. Combination of statin plus renin angiotensin system inhibition for the prevention or the treatment of atherosclerotic cardiovascular disease. Curr Pharm Des. 2014; 20(40): 6299-6305, doi: 10.2174/1381612820 666140620115756, indexed in Pubmed: 24953400.

21. Pfeffer MA, McMurray J, Leizorovicz A, et al. Valsartan in acute myocardial infarction trial (VALIANT): rationale and design. Am Heart J. 2000; 140(5): 727-750, doi: 10.1067/mhj.2000.108832, indexed in Pubmed: 11054617.

22. Cleland JG, Erhardt L, Murray G, et al. Effect of ramipril on morbidity and mode of death among survivors of acute myocardial infarction with clinical evidence of heart failure. A report from the AIRE Study Investigators. Eur Heart J. 1997; 18(1): 41-51, indexed in Pubmed: 9049514.

23. Stenestrand U, Wallentin L. Swedish Register of Cardiac Intensive Care (RIKS-HIA) Early statin treatment following acute myocardial infarction and 1-year survival. JAMA. 2001; 285(4): 430-436, doi: 10.1001/jama.285.4.430, indexed in Pubmed: 11242427.

24. Koh KK, Quon MJ, Han SH, et al. Additive beneficial effects of losartan combined with simvastatin in the treatment of hypercholesterolemic, hypertensive patients. Circulation. 2004; 110(24): 3687-3692, doi: 10.1161/01.CIR.0000143085.86697.13, indexed in Pubmed: 15569835.

25. Fox KM. EURopean trial On reduction of cardiac events with Perindopril in stable coronary Artery disease Investigators. of perindopril in reduction of cardiovascular events among patients with stable coronary artery disease: randomised, double-blind, placebo-controlled, multicentre trial (the EUROPA study). The Lancet. 2003; 362(9386): 782-788, doi: 10.1016/s01406736(03)14286-9, indexed in Pubmed: 13678872.

26. Yusuf S, Sleight P, Pogue J, et al. Heart Outcomes Prevention Evaluation Study Investigators. Effects of an angiotensinconverting-enzyme inhibitor, ramipril, on cardiovascular events in high-risk patients. N Engl J Med. 2000; 342(3): 145-153, doi: 10.1056/NEJM200001203420301, indexed in Pubmed: 10639539. 